\title{
An Efficiency Analysis of Chinese Coal Enterprises by Using Malmquist Productivity Indexes
}

\author{
Yuzhen $\operatorname{Tian}^{1, a}$, Zhanxin Ma ${ }^{1, b_{*}}$ \\ ${ }^{1}$ School of Economics and Management, Inner Mongolia University, Hohhot 010021, China \\ ahs_tianyuzhen@163.com, bem_mazhanxin@imu.edu.cn
}

\begin{abstract}
Keywords: Malmquist productivity indexes, data envelopment analysis, comprehensive evaluation, DEA Efficiency

Abstract: Under strategies of sustainable development, it is worth analyzing the matter of energy efficiency, therefore, how to improve the energy efficiency of enterprises has a very important significance. In order to effectively evaluate and analyze the economic efficiency of Chinese coal enterprises, this paper uses the method of Malmquist productivity index based on DEA method, and then selects Chinese 15 listed coal enterprises as the object of study and evaluates their efficiency. The sample period is from 2004 to 2014. The results show that the total factor productivity (TFP) of most companies appear a growth trend. Some declined in the TFP of the enterprise is also decline in Technological Change (TC). Therefore, companies should still focus on improving technological progress and technological innovation.
\end{abstract}

\section{Introduction}

With the rapid growth of economy, the demand of energy is increasingly growing. And thus the following energetic problem becomes more serious. Meanwhile, in China, the coal is the main energy and holds dominant position, and it is also the pillar of the economy. Therefore, how to improve the energy efficiency through its business restructuring becomes a worthy discussion. Recently, many domestic scholars use the DEA method to study deeply the efficiency of the coal industry. The paper [1] measures the efficiency of Coal Mine Listed Enterprise by the means of DEA in batches, and puts forward the improved methods according to the improvement results. In the paper [2], DEA was applied to evaluate the operating efficiency of 20 large coal enterprises in China. It turned that most of the coal business are inefficient, mainly due to idle assets, redundant personnel and the constraints of size; finally, this paper explored the way of improving the operating efficiency of coal enterprises. In the paper [3] 40 coal enterprises panel data were taken as the researching samples, DEA and SFA methods were united to evaluate efficiency of the coal enterprises from 2004 to 2006 and the relativity and coincidence were tested. By using the $C^{2} R$ model of DEA, the paper [4] analyzed the operating performance of Chinese 17 coal enterprises listed companies based on the data from their recent 2 years' annual reports. By using generalized DEA methods, the paper [5] analyzes Chinese coal listed companies from 2000 to 2008 panel data.

DEA method for the analysis of production efficiency has its own advantage, but the using of traditional DEA methods sometimes appears that not only one DMU are effective, so it is difficult to compare the differences among enterprises. In this paper, a method of Malmquist index to measure the productivity of enterprises has its own advantages which don't need to assume a specific function in case of appearing errors of function designing ${ }^{[6]}$. This method decomposes TFP which comprises by technological change(TC), pure technical efficiency change(PTEC) and scale efficiency change(SEC). The results with this method may be greater than 1 , but it is possible to order all DMUs, which is advantage to make analysis. The other advantage is that it studies the stable and regulatory period of coal industry. Meanwhile, using Malmquist productivity index and analyzing the various factors that may affect the efficiency of enterprises, this paper can take a more objective analysis.

Malmquist Productivity Index Model.Malmquist index was originally proposed by Malmquist Sten ${ }^{[7]}$. In 1982, Caves et al applied Malmquist index to the problem of calculating productivity changes firstly ${ }^{[8]}$, after which researchers combine it with DEA theory, because of its better 
characterize the efficiency of relative dynamic changes, Malmquist productivity index was used widely ${ }^{[9]}$. This paper uses Malmquist index in DEAP software to calculate.

When one has panel data, one may use DEA-like linear programs and a (input-or output-based) Malmquist TFP index to measure productivity change, and to decompose this productivity change into technical change and technical efficiency change ${ }^{[10]}$.

Fare et al (1994) specifies an output-based Malmquist productivity change index as:

$$
\mathrm{M}\left(\boldsymbol{x}_{t}, \boldsymbol{y}_{t}, \boldsymbol{x}_{t+1}, \boldsymbol{y}_{t+1}\right)=\left[\frac{D^{t}\left(\boldsymbol{x}_{t+1}, \boldsymbol{y}_{t+1}\right)}{D^{t}\left(\boldsymbol{x}_{t}, \boldsymbol{y}_{t}\right)} \times \frac{D^{t+1}\left(\boldsymbol{x}_{t+1}, \boldsymbol{y}_{t+1}\right)}{D^{t+1}\left(\boldsymbol{x}_{t}, \boldsymbol{y}_{t}\right)}\right]^{\frac{1}{2}}
$$

This represents the productivity of the production point $\left(\boldsymbol{x}_{t+1}, \boldsymbol{y}_{t+1}\right)$ relative to the production point $\left(\boldsymbol{x}_{t}, \boldsymbol{y}_{t}\right)$. A value greater than one will indicate positive TFP growth from period to period $t+1$. This index is, in fact, the geometric mean of two output-based Malmquist TFP indices. One index uses period t technology and the other period $t+1$ technology. To calculate, we must calculate the four component distance functions, which will involve four LP problems (similar to those conducted in calculating Farrell technical efficiency(TE)measures).

We begin by assuming CRS technology (we conduct a further decomposition later to look at scale efficiency questions). Except that the convexity(VRS) restriction has been removed and time subscripts have been included. That is,

$$
\begin{aligned}
& {\left[D^{t}\left(\boldsymbol{x}_{t}, \boldsymbol{y}_{t}\right)\right]^{-1}=\max _{\varphi, \lambda} \varphi,} \\
& \text { s.t. }-\varphi \boldsymbol{y}_{i t}+\boldsymbol{Y}_{t} \boldsymbol{\lambda} \geq \mathbf{0}, \\
& \boldsymbol{x}_{i t}-\boldsymbol{X}_{t} \boldsymbol{\lambda} \geq \mathbf{0}, \\
& \quad \boldsymbol{\lambda} \geq \mathbf{0},
\end{aligned}
$$

The remaining three LP problems are simple variants of this

$$
\begin{aligned}
& {\left[D^{t+1}\left(\boldsymbol{x}_{t+1}, \boldsymbol{y}_{t+1}\right)\right]^{-1}=\max _{\varphi, \lambda} \varphi,} \\
& \text { s.t. }-\varphi \boldsymbol{y}_{i, t+1}+\boldsymbol{Y}_{t+1} \lambda \geq \mathbf{0}, \\
& \boldsymbol{x}_{i, t+1}-\boldsymbol{X}_{t+1} \lambda \geq \mathbf{0}, \\
& \lambda \geq \mathbf{0}, \\
& {\left[D^{t}\left(\boldsymbol{x}_{t+1}, \boldsymbol{y}_{t+1}\right)\right]^{-1}=\max _{\varphi, \lambda} \varphi,} \\
& \text { s.t. }-\varphi \boldsymbol{y}_{i, t+1}+\boldsymbol{Y}_{t} \lambda \geq \mathbf{0}, \\
& \boldsymbol{x}_{i, t+1}-\boldsymbol{X}_{t} \lambda \geq \mathbf{0}, \\
& \quad \lambda \geq \mathbf{0}, \\
& {\left[D^{t+1}\left(\boldsymbol{x}_{t}, \boldsymbol{y}_{t}\right)\right]^{-1}=\max _{\varphi, \lambda} \varphi,} \\
& \text { s.t. }-\varphi \boldsymbol{y}_{i, t}+\boldsymbol{Y}_{t+1} \lambda \geq \mathbf{0}, \\
& \boldsymbol{x}_{i, t}-\boldsymbol{X}_{t+1} \lambda \geq \mathbf{0}, \\
& \lambda \geq \mathbf{0},
\end{aligned}
$$

Note that in LP's Eq.4 and Eq.5, where production points are compared to technologies from different time periods, the $\varphi$ parameter does not need to be greater than or equal to 1 , as it must be when calculating Farrell efficiencies. The point could lie above the feasible production set. This will most likely occur in LP'sEq. 4 where a production point from period $t+1$ is compared to technology in period $t$. If technical progress has occurred, then a value of $\varphi<1$ is possible. Note that it could also possibly occur in LP's Eq.5 if technical regress has occurred, but this is less likely.

The Evaluation and Analysis of Total Factor Productivity of Chinese Coal Enterprises

Selection and Establishment of Indexes.This paper selects 15 listed coal enterprises as the 
research objects, and selects those companies' panel data to analyze and evaluate their efficiency from 2004 to 2014. To ensure the comparability of data, this paper will convert all prices to constant prices of 2010. The paper selects total assets, number of employees and the main business cost as the input indicators; Selecting the main business income and gross profit as output indicators. Data are all derived from the respective annual reports of listed companies. This paper is computed in output-oriented, and it assumes constant returns to scale. And through putting the treated data into software of DEAP to compute, results can be acquired.

\section{Analysis and Conclusions}

An analysis of TFP of Chinese Coal Enterprises.By the results of PTEC, TC, the comprehensive technical efficiency change (TEC), Returns to scale change (RSC), TFP growth of 15 Chinese coal enterprises in 2004 2014, we can get their average value showed as Table 1.

Table1. The changes of annual average Malmquist index of Chinese coal enterprises

\begin{tabular}{cccccc}
\hline Year & TEC & TC & PTEC & RSC & TFP growth \\
\hline 2005 & 1.084 & 0.974 & 1.042 & 1.041 & 1.056 \\
2006 & 1.002 & 0.915 & 0.999 & 1.003 & 0.916 \\
2007 & 1.022 & 1.006 & 1.003 & 1.019 & 1.028 \\
2008 & 0.969 & 1.229 & 0.979 & 0.99 & 1.191 \\
2009 & 1.097 & 0.715 & 1.048 & 1.047 & 0.784 \\
2010 & 0.981 & 1.132 & 0.99 & 0.991 & 1.11 \\
2011 & 0.996 & 1.263 & 0.996 & 1 & 1.257 \\
2012 & 0.99 & 1.124 & 0.98 & 1.011 & 1.114 \\
2013 & 1.035 & 1.167 & 1.037 & 0.998 & 1.208 \\
2014 & 0.961 & 1.15 & 0.961 & 1 & 1.105 \\
Mean & 1.013 & 1.054 & 1.003 & 1.01 & 1.068 \\
\hline
\end{tabular}

As can be seen from Table 1, average of TFP of 15 Chinese coal enterprises maintains an upward trend from 2004 to 2014. Except 2009, its TFP is decline dramatically because of the financial crisis. However, from the annual average of 1.068, the total factor productivity of labor still maintains $6.8 \%$ growth.

In 2007 and 2009, the growth rate of TFP is greater than 1. At the same period, its TC is greater than 1. It indicates that the improving of TFP is due to technological progress and technological innovation.

In 2009, the TFP is less than 1. After suffering the financial crisis, companies' technological progress and technological innovation is in decline obviously.

During $2010 \sim$ 2014, the growth rate of TFP is greater than 1. From this, we can see that the economy started to recover after the financial crisis. Meanwhile, TC of these years are all greater than 1, which indicate that companies began to focus on technological progress, and began to focus on technological improvements and innovation. With technology advances efficiency improving, total factor productivity improved significantly.

From the point of RSC, its average change is greater than 1, it shows that the average RSC of Chinese coal enterprises are in growth.

We can see from the TEC from 2004 to 2014, the average generally keeps growth, except for some minor changes in outer years. This shows that TEC of Chinese coal enterprises rise steadily, which also guarantee the growth rate of TFP.

\section{Analysis of average TFP of Chinese Coal Enterprises}

Table 2. The changes of annual average Malmquist index of 15 coal enterprises in china

\begin{tabular}{cccccc}
\hline Name & TEC & TC & PTEC & RSC & TFP \\
\hline Shenhuo & 1 & 1.39 & 1 & 1 & 1.39 \\
Jizhong & 1.011 & 1.115 & 1.007 & 1.004 & 1.127 \\
Meiqihua & 0.971 & 1.094 & 0.964 & 1.008 & 1.063 \\
Xishan & 1.036 & 1.165 & 1.034 & 1.002 & 1.207 \\
\hline
\end{tabular}




\begin{tabular}{cccccc}
\hline Zhenzhou & 1.023 & 1.011 & 1.016 & 1.007 & 1.035 \\
Lanhua & 1.015 & 0.883 & 1.005 & 1.01 & 0.896 \\
Yanzhou & 1 & 1.616 & 1 & 1 & 1.616 \\
Panjiang & 1.015 & 0.99 & 1.005 & 1.009 & 1.004 \\
Shanghai & 1 & 0.931 & 1.001 & 0.999 & 0.931 \\
Aishi & 1.018 & 0.936 & 1.012 & 1.006 & 0.952 \\
Anyuan & 1.026 & 0.95 & 1.011 & 1.015 & 0.975 \\
Guoyang & 0.99 & 1.023 & 0.995 & 0.995 & 1.013 \\
Jinrui & 1.07 & 0.955 & 1 & 1.07 & 1.022 \\
Hengyuan & 1.002 & 0.913 & 0.984 & 1.019 & 0.915 \\
Kailuan & 1.019 & 1.061 & 1.013 & 1.006 & 1.081 \\
Mean & 1.013 & 1.054 & 1.003 & 1.01 & 1.068 \\
\hline
\end{tabular}

As can be seen from Table 2, average annual growth rate of TFP from 2004 to 2014 in Chinese coal enterprises is greater than 1. It indicates that overall coal enterprises' TFP present an upward trend with an average growth rate of 6.8\%. From the view of enterprises, except Lanhua, Aishi, Anyuan and Hengyuan of which TFP are less than 1, the other enterprises' TFP are all greater than 1. As can be seen from the Table 2, the four companies mentioned above have a common characteristic which is that their TFP are all less than 1. It reflects that technological progress and technological innovation of these four companies are in decline. Thus, the deficiency of TC impedes the growth rate of TFP.

From the perspective of TC, besides the four companies mentioned above, Panjiang, Shanghai and Jinrui of which TC are less than 1. Improve efficiency remaining eight technology companies is greater than 1 . Nearly half of enterprises in technological progress and technological innovation are showing declining trend, which indicate that there are most companies do not realize that with the advent of knowledge economy, technological innovation is increasingly becoming a decisive factor of efficient advancing and competitive advantage.

From the PETC situation, Meiqihua, Guoyang and Hengyuan of which PETC are less than 1, and the rest are greater than 1 . As can be seen from the Table 2, most of companies of which PTEC is in growth, meanwhile, their TEC are increase. That indicates that the improving of PETC is a dominate factor of improving of TEC.

From the perspective of RSC, the indexes of most coal enterprises is greater than 1 in RSC, it shows that Chinese coal enterprises totally present an upward trend.

From the analysis showed above, the growth rate of TFP of Chinese listed coal companies is the impetus of TC. From the mean value, each index of the 15 listed coal companies has reached 1, it indicates that each element is in uptrend. However, comparing to other indexes, the growth of PETC is slightly slower than others, which shows that every enterprise should pay more attention to enhancing the efficiency of technology.

\section{Acknowledgements}

This work is financially supported by National Natural Science Foundation of China (71271084, 71261017, 70961005) and Tianjin Education Commission of Social Sciences major projects (2012ZD35).

\section{References}

[1] Hao Qingmin, Zhao Guojie, Sun Lihong. Measuring the Efficiency of the Coal Mine Listed Enterprises Based on DEA [J]. China University of Geosciences, 2003, 3(2):38-40.

[2] Rao Tiantian, Lv Tao. Operating efficiency of Chinese large coal enterprises based on DEA [J]. China Mining Industry,2009, 18(8): 27-31.

[3] Yao Ping, Liang Jingguo, Measurement of Chinese coal enterprises efficiency[J]. Journal of China Coal Society,2008,33(3) 
[4] Peng Yingke, Zhang Wen. Operating Performance Analysis on China's Coal Enterprises Listed Companies [J]. Economic Mathematics, 2010, 27(1)

[5] Ma Zhanxin, Wen Xiujing. Using DEA Method Based on Panel Data to Analysis of the Energy Efficiency and Energy Enterprise Efficiency [D]. Inner Mongolia University, 2010.

[6] Qu XiaoE, China’s Interprovincial Total Factor Energy Efficiency Change Decomposes [J], The Chinese Provincial Total Factor Decomposition Energy Efficiency Change,2009, 10(1):30-31

[7] Malmquist S. Index numbers and indifference curves[J]. Trabajos de Estadistica, 1953, 4: 209-242

[8] Caves D W, Christensen L R, Diewert W E. The economic theory of index numbers and the measurement of input, output, and productivity[J]. Econometrica, 1982, 50: 1393-1414

[9] Ma Zhanxin. Data envelopment analysis(DEA) and Its Application Cases [M]. Beijing: Science Press,2013:188-202

[10] Fare R., Grosskopf S, M. Norris, Z. Zhang (1994), Productivity Growth, Technical Progress, and Efficiency Changes in Industrialised Countries, American Economic Review,84,66-83. 